\title{
Genetic fact-check for ageing story
}

A genetic study of healthy elderly people aims to uncover the secret of living to a ripe old age - intact.

The 'Wellderly Study' is a joint initiative between the Scripps Research Institute in La Jolla, California, and scientists at the J. Craig Venter Institute in Rockville, Maryland. It hopes to investigate the genomes of 2,000 people aged 80 or more who take no significant medication and have never suffered from any serious disease.

"We are looking at a cohort that we think is harbouring major secrets. They have disease susceptibility genes, but they don't get the diseases you would have expected. Something has protected them. We hope to find out what that is," says study leader Eric Topol, who is director of genomic medicine at Scripps.

Topol and his team will compare gene sequences from their subjects with the same genes in tissues from a control group they've dubbed the 'illderly'. This second group covers people who died from common, age-related diseases such as cancer, heart attack and stroke before they made it to 80 .

Topol and his colleagues Robert Strausberg and Samuel Levy at the Venter Institute finalized their list of 100 candidate genes last week. It includes genes with an unknown or putative role in healthy ageing, and some that are involved in key jobs such as DNA repair and the handling of insulin. The team plans to expand the list to 500 genes over several years and ultimately to sequence the whole genomes of their elderly recruits. So far, the affiliated Scripps Health System has provided the bulk of the costs of the study.

In principle, the study is "the perfect idea", says Giuseppe Paolisso, a geriatrics expert at the Second University of Naples in Italy, who has studied the relationship between insulin action and longevity. But the problem, he cautions, "is defining which are the major genes".

Topol, whose 360 subjects so far enrolled average 86 years old, is actually working at the youthful end of the spectrum for studies into ageing. Nir Barzilai, for example, who directs the Longevity Genes Project at the Albert Einstein College of Medicine in New York, is

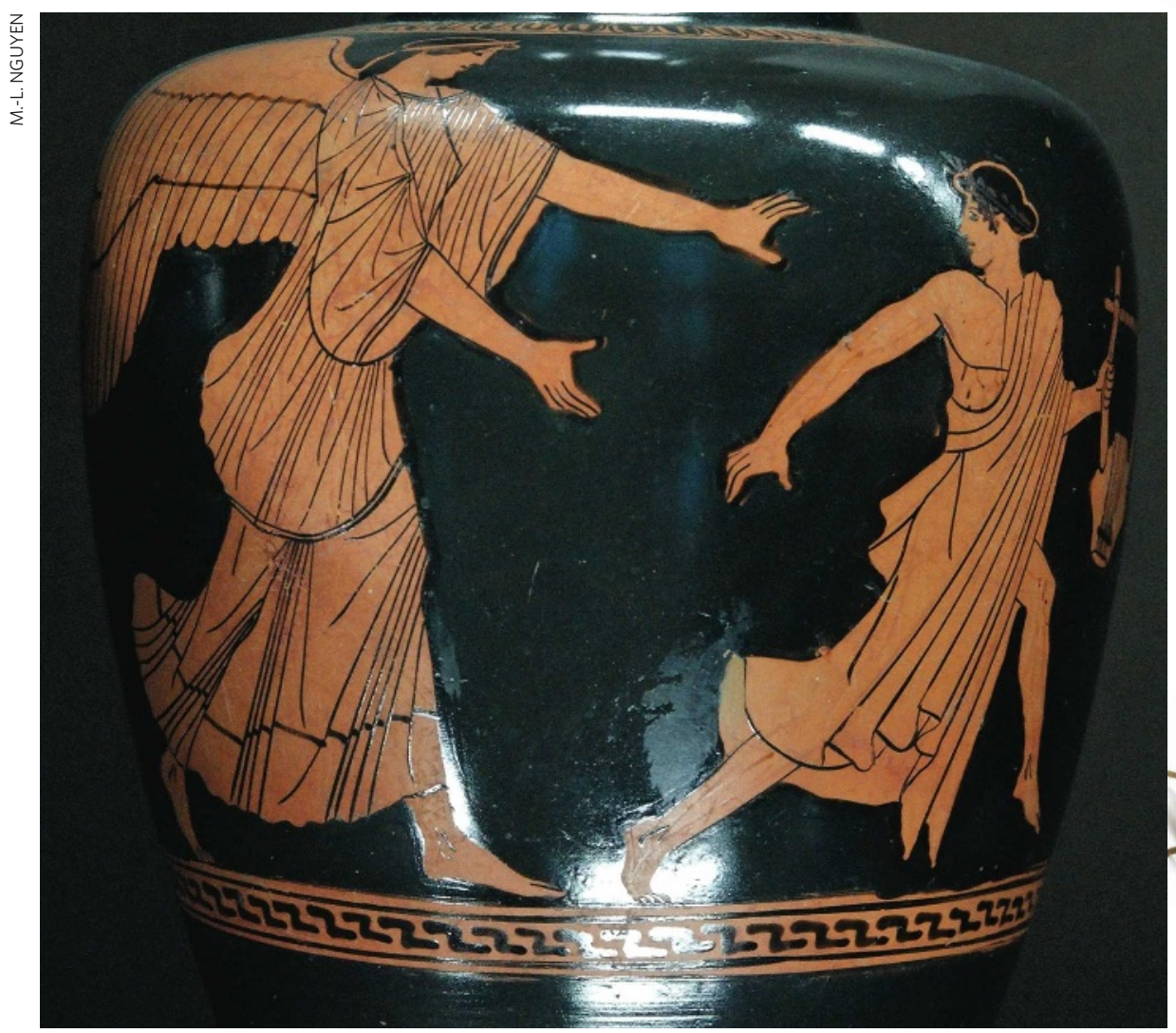

studying Ashkenazi Jews aged 95 and older. Barzilai's team has validated three longevityrelated genes so far.

And Rudi Westendorp and Eline Slagboom at Leiden University Medical Centre in the Netherlands have hunted for longevity-associated genetic variations in a group defined by elderly sibling pairs: men aged 89 and above, and women over 91. Results from this study are expected to be published within months.

\section{"It's like a super- senior Facebook."}

Westendorp praises Topol's study for "addressing the prob-

lem at the heart", by sequencing a wide range of candidate genes. But he says that 80 isn't old enough to rule out a subject surviving in good health simply by chance. "At 80 , you are not yet special," Westendorp says. To ensure that genetic variation is involved, "you have to go for the far extreme of the population", he says.

Topol responds that Westendorp's sibling pairs could have had heart attacks, survived three types of cancer and be cognitively impaired. "We have totally intact people, over 80 , on no medication. They are distinct outliers," he says. "We have a totally different phenotype

- and I think

it's the phenotype that the public is interested in." The search for the genetic roots of longevity is fundamentally different from the wellderly study, says Topol, as his group is focusing on health, not just survival.

Ongoing recruitment to Topol's study is unlikely to be a problem. Subjects "really like to be part of this wellderly group", he says. "It's like a super-senior Facebook. As soon as we recruit people, they start finding all their bridge partners. We are getting calls from all over." Meredith Wadman

The goddess Eos is depicted on this Ancient Greek vase pursuing her human lover Tithonos for whom she requested immortality but forgot to stipulate that he should also have eternal youth. Thus, he aged until he became so wizened he turned into a grasshopper. As longevity increases worldwide, researchers are concentrating their efforts on achieving a 'youthful' old age. 